\title{
A MACROMODEL SUBSTITUTE FOR SIMPLE PREDICTION OF THE LATERAL BEHAVIOUR OF COMPOSITE SHEAR WALLS
}

\author{
Farhad Behnamfar $^{1}$, Esmail Shakeri ${ }^{2}$ and Akbar Makhdoumi ${ }^{3}$
}

(Submitted May 2017; Reviewed September 2017; Accepted July 2018)

\begin{abstract}
Composite shear wall is a structural component consisting of a steel plate connected using shear tabs to a reinforced concrete cover. The steel plate provides for stiffness, strength, and ductility and the concrete cover prevents the steel plate from buckling. In this paper, effects of steel plate's thickness, compressive strength and thickness of the concrete cover and spacing of the shear tabs on the characteristics of the wall in nonlinear lateral behaviour are evaluated and a macromodel substitute for the wall is developed. The macromodel is a generic lateral force-displacement rule for the wall with its characteristics as developed in this paper. Practical ranges of values are accounted for the parameters involved. Such an approach makes it possible to replace the very complicated and time-consuming three-dimensional model of the composite wall with a simple onedimensional element following the nonlinear lateral force-displacement path as given in this paper.
\end{abstract}

\section{INTRODUCTION}

Use of shear walls in structures is a very common option to contain lateral movements under wind forces and to provide for seismic resistance in earthquake prone areas. Although the traditional option for a shear wall has been use of reinforced concrete, in recent years utilizing steel plate shear walls (SPSWs) in steel structures has emerged as an attractive alternative.

An SPSW removes the need for frameworking. Because of its small thickness, it is easily installed as a lightweight infill between its peripheral steel beams and columns. On the other hand, for the same reason, it is vulnerable to corrosion and fire, and more important, to buckling in compression. Adding a reinforced concrete cover to an SPSW on one or both sides makes for a composite shear wall (CSW) and eliminates all of the above problems [1]. Moreover, if it is used as a one-sided cover, the steel plate can act as part of the framework too. Of course, use of a precast concrete cover is also possible.

To prevent the steel plate from buckling, it must be connected to the concrete cover at certain points using shear tabs. Detail of the connection and spacing of the tabs thus are important design considerations. Since the concrete cover acts only as a lateral support for the steel plate, it is enough to make it as a thin cover lightly reinforced to keep it integrated. Besides, there is no need to connect the concrete cover to the floor diaphragms. Instead, the diaphragms have only to be connected to the steel plate of CSW. In spite of the practical advantages of a composite shear wall, it is very complicated for exact finite elements modelling. In such a model, a non-homogeneous three-dimensional (3D) medium of the steel plate, steel reinforcement, and concrete has to be dealt with. The reinforcement has to be modelled with its non-continuous configuration and three different nonlinear stress-strain rules have to be used for the constituting materials. Due to their inherent complexity, research on CSWs has not been as extensive as SPSWs. A non-exhaustive review on the efforts performed in this regard is presented in the following.
Yamakaji and Yamada [2] studied the comparative behaviour of similar SPSW and CSW samples. They reported an increased stiffness 3-7 times larger than a similar moment frame system with the use of a CSW within a steel structure. Also, the lateral strength exhibited a 2-3 times increase. In contrast, ductility of the system did not show a considerable improvement.

Zhao and Astaneh-Asl [3] studied a one-sided CSW. Experimental studies included two half-scale three-story composite shear wall specimens. Results confirmed a highly ductile behaviour and stable cyclic post-yielding performance. The study also illustrated that the gap between the frame members and the RC panel provided better ductility and higher energy dissipation capacity compared with the specimens without gap. Moreover, Zhao and Astaneh-Asl [4] investigated the cyclic behaviour of CSWs through performing experiments and numerical analysis. They utilized a one-sided CSW in their work, and showed that close enough spaced shear tabs can effectively prevent the steel plate from elastic buckling. Thus, considerable improvement of cyclic characteristics of an SPSW was shown to be achievable with using a concrete cover. It was also exhibited that making a small gap between the cover and the boundary elements (such as beams and columns) of the perimeter of a wall further enhances its characteristics and prevents the concrete cover from premature failure in compression.

Choi and Park [5] developed a hysteresis model of the infill steel plate for cyclic analysis of SPSWs. Based on the analysis results, the hysteretic behaviour of the infill steel plate was simplified as an equivalent uniaxial stress-strain relationship in the direction of tension-field action. The equivalent tension brace model was utilized to predict the capacity of the steel plate and the forces distributed in the boundary members with good accuracy.

Qu et al. [6] tested a full-scale two-storey steel plate shear wall with reduced beam section (RBS) connections and composite floors. First, the specimen was pseudo dynamically tested and the buckled panels were replaced by new ones prior to performing a subsequent cyclic test to failure. It was shown that

\footnotetext{
Corresponding Author, Associate Professor, Department of Civil Engineering, Isfahan University of Technology, Esfahan 8415683111, Iran, farhad@cc.iut.ac.ir

Senior Earthquake Engineer, Esfahan, Iran, shakeri.esmail@yahoo.com

3 PhD Student, Department of Civil Engineering, Isfahan University of Technology, Esfahan 8415683111, Iran, makhdoumi.ar@gmail.com
} 
the repaired specimen could survive and dissipate significant amounts of hysteretic energy in a subsequent earthquake without severe damage to the boundary frame or overall strength degradation.

Hatami and Rahai [7] studied effects of parameters like beamcolumn connection type, shear tab spacing, and thickness of the concrete cover in stiffened and non-stiffened CSWs. They analysed finite element models of the same walls and observed a lateral strength increasing with the thickness of concrete cover and decreasing with the shear tab spacing. The lateral behaviour of wall was shown to be insensitive to the type of beam-column connection. Arabzadeh et al. [8] investigated the experimental behaviour of CSWs under shear loadings. The results indicated that this system has a reliable behaviour if the columns have high bending stiffness. Also, ratio of bolts spacing to plate thickness showed a direct relationship with the system ductility. However, the plate yield load had an inverse relationship with the above ratio. Also, the results were in good agreement with the recommended values of $\mathrm{b} / \mathrm{t}$ by the AISC regulations for preventing local buckling.

Husem et al. [9] performed cyclic experiments of CSWs with different details of shear tabs. They studied use of shear studs, and single or double I-profile and U-profile segments. As a result, the U-profiles showed the minimum and double Iprofiles the maximum contribution to increase of lateral strength of wall. Ayazi et al. [10] studied role of different detailing of shear tabs on lateral behaviour of systems equipped with CSWs. For this purpose, they analysed a regular 14-story single-bay steel frame having CSWs in all stories. Different spacings were evaluated and maximum and minimum admissible distances between the shear tabs were suggested to enhance the lateral behaviour.

Guo et al. [11] investigated the cyclic behaviour of SPSW and CSW in composite frames. The tested shear wall system consisted of concrete-filled circular hollow section steel columns, steel beams, and SPSW or CSW. The experimental results showed that the CSW system possessed good ductility and energy dissipation capacity.

Dastfan and Driver [12] studied the behaviour of SPSWs with partially encased composite columns. They tested a large-scale modular steel plate shear wall to observe and quantify some key characteristics. It was shown that the utilized modular construction method had very little effect on the overall behaviour as the specimen exhibited high initial stiffness, good displacement ductility and high energy dissipation capacity. Presence of longitudinal rebars at the bases of the columns proved to have an important effect on the overall behaviour of the specimen. The same authors (Dastfan and Driver) [13] also tested a large-scale SPSW with partially encased composite columns and RBS connections. Characteristics including the lateral stiffness, ductility, and energy dissipation capacity were determined. The results showed that use of RBS frame connections improved the seismic performance of the walls.

Rahnavard et al. [14] studied the important parameters such as concrete strength, hysteresis response, out of plane displacement, frame drift, and dissipated energy of CSWs. The findings revealed that the system with concrete on one side of the shear plate had $\mathrm{s}$ better energy dissipation function compared with other types of the composite wall. The energy dissipation capacity was increased by reducing the connectors' distances. Rassouli et al. [15] performed an experimental and numerical study on CSW with its cover made of light-weight concrete. The results indicated that the mentioned system was reliable for carrying the lateral loads in a steel structure. Specifically, shear capacity of the system was similar to the one with a normal-weight concrete panel.

Sabouri-Ghomi et al. [16] developed a closed-form solution for the analysis and design of CSWs subjected to out-of-plane loads using the partial interaction theory. As a result, the deformation and stress distribution of the wall were estimated. Also, the results demonstrated that both steel plate and especially the concrete cover were effective in limiting the out-of-plane deformation. The shear connector spacing was effective also to the same order and the out-of-plane deformation increased with distancing the shear connectors.

Shafaei et al. [17] investigated the effect of concrete panel thickness upon CSW. It was shown that the reinforced concrete panel thickness had a remarkable and direct influence upon the shear capacity and the ultimate strength of CSW. A reinforced concrete panel with a thickness of $12.5 \mathrm{~cm}$ was a good companion for a steel plate thickened $4 \mathrm{~mm}$ and resulted in about $40 \%$ increase of the system ductility. Bruhl and Varma [18] experimentally investigated the lateral strength and ductility of CSWs. The experimental results included the elastic stiffness and yield capacity, postyield behaviour up to the ultimate failure, the moment-curvature behaviour, and the deformation and curvature ductility of the specimens.

Review of the related literature as above shows that questions are persisting about the lateral behaviour of CSWs. Especially, in order to develop reliable design relations, effects of different parameters have to be studied more extensively. This study, with a different viewpoint, aims to develop a generic forcedisplacement relation, or a macromodel, for CSWs. Such a tool can be very useful in simplifying the finite elements modelling of such a complex wall. The macromodel of the current research is meant to simply estimate the lateral stiffness, strength, and ductility of CSWs, in spite of the work of Choi and Park [5] that is for SPSWs. The mentioned parameters completely define a bilinear representation (or approximation) of the lateral forcedisplacement curve. This in turn makes it possible for the wall to be replaced, in computer modelling, with a much simpler one-dimensional diagonal element having nonlinear characteristics.

\section{NUMERICAL MODELING AND VALIDATION}

To begin with the finite element modelling, the experimental CSW of Zhao and Astaneh-Asl [4] is selected for validation analysis. The reason for this selection is availability of enough details of the wall and its tests and analysis and its suitability for the purposes of this study. Figure 1 shows the view of this wall mentioning its dimensions. It is composed of three inheight transverse beams, two side columns, and rigid boundaries at top and bottom. The steel plates are continuously connected to their peripheral beams and columns. A reinforced concrete layer covers the steel plate on one side.

Dimensions of the wall components and their mechanical characteristics are mentioned in Tables 1-3. As these tables show, the steel plate is of the mild steel type being of St37 European or A36 American grade. On the other hand, the peripheral beams and columns are of the stronger St52 steel. It means that the wall, as the seismic fuse of the system, has been proportioned in a way to ease yielding of the steel plate before that of other members. Also, the concrete material of the cover has been selected to be strong enough as seen with its compressive strength.

The stress-strain relation of concrete is assumed to follow the modified Hognestad equation as follows:

$\mathrm{f}_{\mathrm{c}}=\mathrm{f}^{\prime \prime}{ }_{\mathrm{c}}\left[2 \frac{\varepsilon_{\mathrm{c}}}{\varepsilon_{0}}-\left(\frac{\varepsilon_{\mathrm{c}}}{\varepsilon_{0}}\right)^{2}\right]$

in which:

$\mathrm{f}^{\prime \prime}{ }_{\mathrm{c}}=\mathrm{K}_{\mathrm{s}} \mathrm{f}^{\prime}{ }_{\mathrm{c}}$

$\varepsilon_{0}=1.8 \frac{\mathrm{f}^{\prime \prime} \mathrm{c}}{\varepsilon_{\mathrm{c}}}$

$\mathrm{E}_{\mathrm{c}}=4700 \sqrt{\mathrm{f}_{\mathrm{c}}^{\prime}}$ 
where $\mathrm{f}_{\mathrm{c}}$ and $\varepsilon_{\mathrm{c}}$ are concrete's stress and strain, and, $\mathrm{E}_{\mathrm{c}}$ and $\mathrm{f}^{\prime}{ }_{\mathrm{c}}$ are its modulus of elasticity and ultimate compressive strength, respectively. $\mathrm{K}_{\mathrm{s}}$ is a factor which is equal to $1,0.97,0.95,0.93$ and 0.92 for concrete strengths equal to $15,20,25,30$, and larger than $30 \mathrm{MPa}$, respectively. Figure 2 shows the stressstrain relation of different steel components of the system.

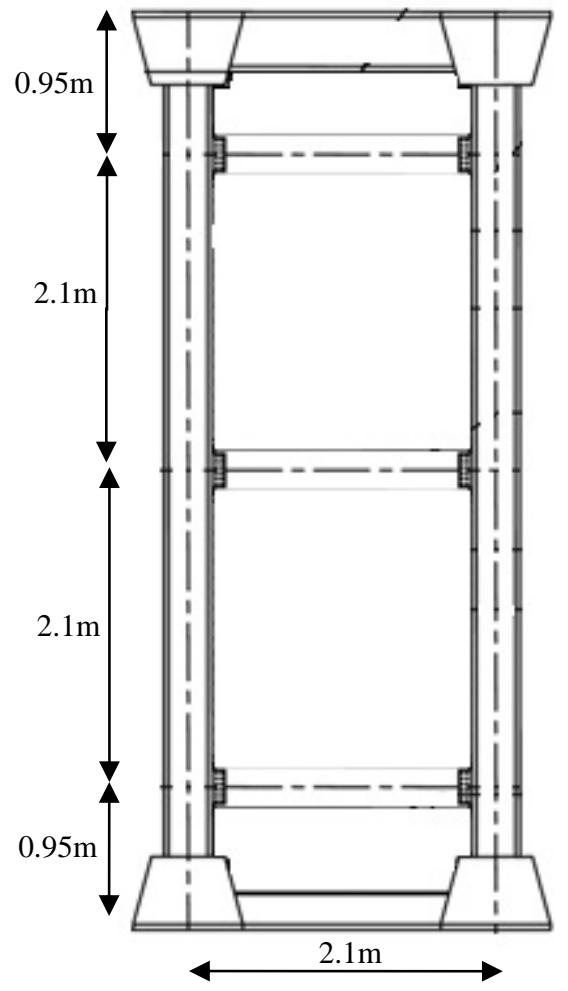

Figure 1: View of the experimental wall selected for validation study (Zhao and Astaneh-Asl, 2007).

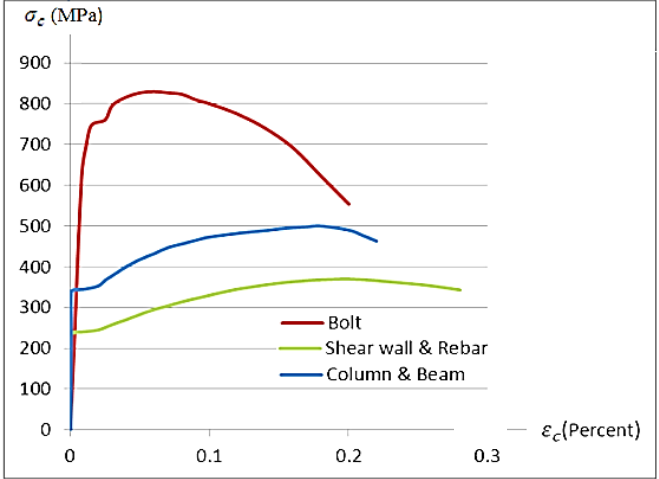

Figure 2: Stress-strain relations of steel.

In this study, the numerical analysis is performed using Abaqus [19]. For modelling of steel beams, columns, and wall plate, use is made of nonlinear two-dimensional (2D) shell elements. Where possible, utilizing the above element type instead of 3D solid elements considerably reduces the computation time. The concrete cover is modelled with nonlinear solid elements. Use of this element makes it possible to follow the real geometry with more accuracy. The steel reinforcement and shear tab segments inside concrete are modelled as a wire (i.e. a 1D nonlinear element). Bending of a beam element and extension/contraction of a truss element are used to model the shear tabs and rebars, respectively.

The beams, columns, steel plates, reinforcement, shear tabs, and concrete elements are merged to work together in the model. To be consistent with the experimental set-up, base of the columns is prevented from translation in any direction. At top of the wall, translation only in the wall plane is set to be free. Loading on the system is a horizontal translation at top of the wall. Figure 3 shows the final FE mesh of the wall after performing a mesh sensitivity analysis. Dimension of all elements in different parts of the shear wall is $100 \mathrm{~mm}$.

Table 1: Component dimensions of the selected CSW (Zhao and Astaneh-Asl, 2007).

\begin{tabular}{|c|c|c|c|c|c|c|}
\hline \multirow{2}{*}{$\begin{array}{l}\text { Wall plate } \\
\text { thickness }\end{array}$} & \multicolumn{3}{|c|}{ Pre-cast RC wall } & \multirow{2}{*}{$\begin{array}{l}\text { Wall bolts } \\
\text { dia. }\end{array}$} & \multirow{2}{*}{$\begin{array}{l}\text { Beam } \\
\text { section }\end{array}$} & \multirow{2}{*}{ Column section } \\
\hline & Thickness & Rebar dia. & Rebar spacing & & & \\
\hline $4.8 \mathrm{~mm}$ & $76 \mathrm{~mm}$ & $10 \mathrm{~mm}$ & $102 \mathrm{~mm}$ & $13 \mathrm{~mm}$ & W12×26 & $W 12 \times 120$ \\
\hline
\end{tabular}

Table 2: Mechanical characteristics of concrete of the CSW (Zhao and Astaneh-Asl, 2007).

\begin{tabular}{|c|c|c|c|c|}
\hline $\begin{array}{c}\text { Compressive strength } \\
\text { (MPa) }\end{array}$ & $\begin{array}{c}\text { Tensile strength } \\
\text { (MPa) }\end{array}$ & $\begin{array}{c}\text { Modulus of elasticity } \\
\text { (MPa) }\end{array}$ & $\begin{array}{c}\text { Poisson's } \\
\text { ratio }\end{array}$ & Ultimate strain \\
\hline 28 & 2.6 & 24900 & 0.17 & 0.003 \\
\hline
\end{tabular}

Table 3: Mechanical characteristics for the steel plate and reinforcement used in the CSW (Zhao and Astaneh-Asl, 2007).

\begin{tabular}{|c|c|c|c|c|c|}
\hline Characteristics & $\begin{array}{c}\text { Modulus of elasticity } \\
\text { (MPa) }\end{array}$ & $\begin{array}{c}\text { Yield strength } \\
\text { (MPa) }\end{array}$ & $\begin{array}{c}\text { Ultimate strength } \\
\text { (MPa) }\end{array}$ & $\begin{array}{c}\text { Ultimate } \\
\text { strain }\end{array}$ & $\begin{array}{c}\text { Poisson's } \\
\text { ratio }\end{array}$ \\
\hline Beam \& Column & 200,000 & 345 & 500 & 0.22 & 0.3 \\
\hline Steel plate \& Rebar & 140,000 & 248 & 370 & 0.28 & 0.3 \\
\hline Bolt & 200,000 & 623 & 823 & 0.2 & 0.3 \\
\hline
\end{tabular}




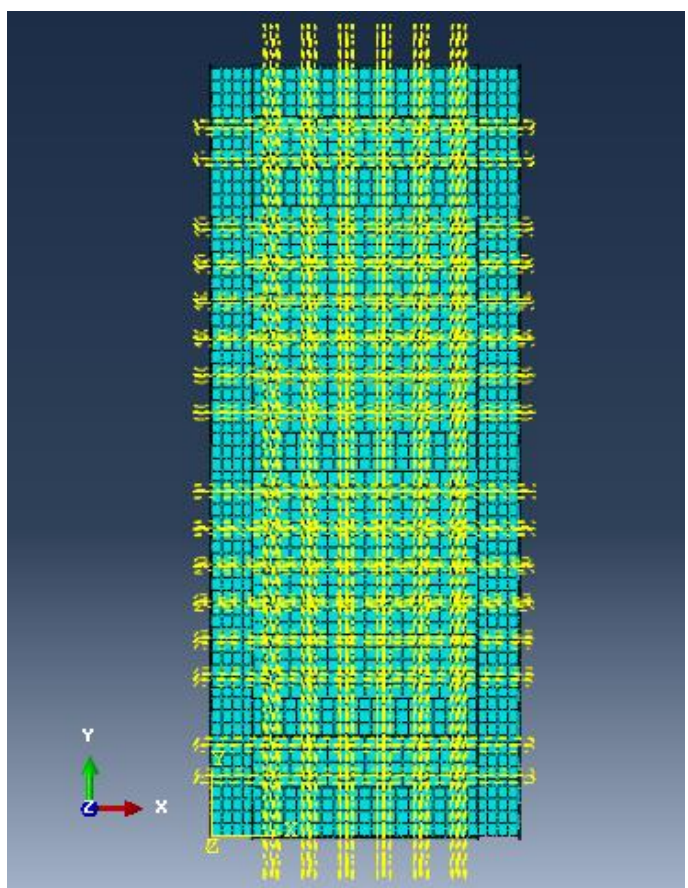

Figure 3: Finite element mesh of the wall.

Numbers of elements are: for concrete 1584 , for steel plate 874 , for beams 703, and for columns 1512 .

It is to be mentioned that throughout this study only the monotonic behaviour of CSWs is studied. Accordingly, in Figure 4, the calculated lateral force-displacement monotonic pushover path of the wall is compared with its experimental cyclic behaviour.

Although comparing a monotonic force-displacement curve with a cyclic one is not conceptually valid, still it can give a relative reliability to the outcome of the analysis. Figure 4 shows that the calculated path closely envelopes the cyclic curves that is an appropriate result. In Zhao and Astaneh-Asl [4], details of initiation and development of nonlinear behaviour in the above system have been described. According to the above reference, large plastic deformations occur in the column flange at the base, in the web of beams, at the connection of the steel plate to its surroundings, and in the corners of the concrete cover. Also, inelastic buckling happens at the flange of columns, web of the beams, and more extensively in the wall plate. The above events are quite similar to what is observed in the push-over analysis of this study as will be shown in the parametric study section. Failure of the system, according both to the analysis and test, is due to tension yielding of the steel plate and formation of plastic hinges at the base of columns and ends of beams.

With the developed numerical model copying accurately enough what is observed during the experiment, it is validated to be used for the following parametric study.

\section{PARAMETRIC STUDY}

\section{General Assumptions}

In order to be able to develop a macromodel containing the essential features of lateral behaviour of a general CSW, it is necessary to quantify effects of important factors involved. Review of the past research and engineering judgment lead to the conclusion that factors including plate thickness, thickness and compressive strength of the concrete cover and spacing of the shear tabs should be the prime factors affecting the lateral behaviour of CSW's. It should be added that detail of connection of the steel plate to its boundary elements should also incorporate local features of the lateral behaviour. It is deemed to be localized and will be studied in a separate work.

In this study, the wall plate is connected to its surroundings at the nodal points of the FE mesh, being an almost continuous connection. To study the lateral behaviour, use is made of conventional values for the mentioned parameters. For the thickness of the steel plate nine values are taken as: $1,2,3,4$, 4.5, 5, 5.5, 6, and $6.5 \mathrm{~mm}$. Five different thicknesses are taken for the concrete cover as: $30,40,50,60$, and $75 \mathrm{~mm}$, five values for the shear tab spacing: $150,300,450,600$, and $750 \mathrm{~mm}$ and five values for the compressive strength of concrete: 14, 21, 25, 28 , and $35 \mathrm{MPa}$.

The above models are analysed under a monotonic lateral displacement at the top being up to $500 \mathrm{~mm}$. Regarding the wall height in Figure 1, the mentioned displacement corresponds to a drift ratio of about $1 \%$, similar to the tested wall. The general dimensions of the CSW and number of elements and size of the FE mesh are similar to the wall analysed in the numerical modelling section (Figures 1 and 2) and the mechanical properties not mentioned above are similar to Tables 1-3.

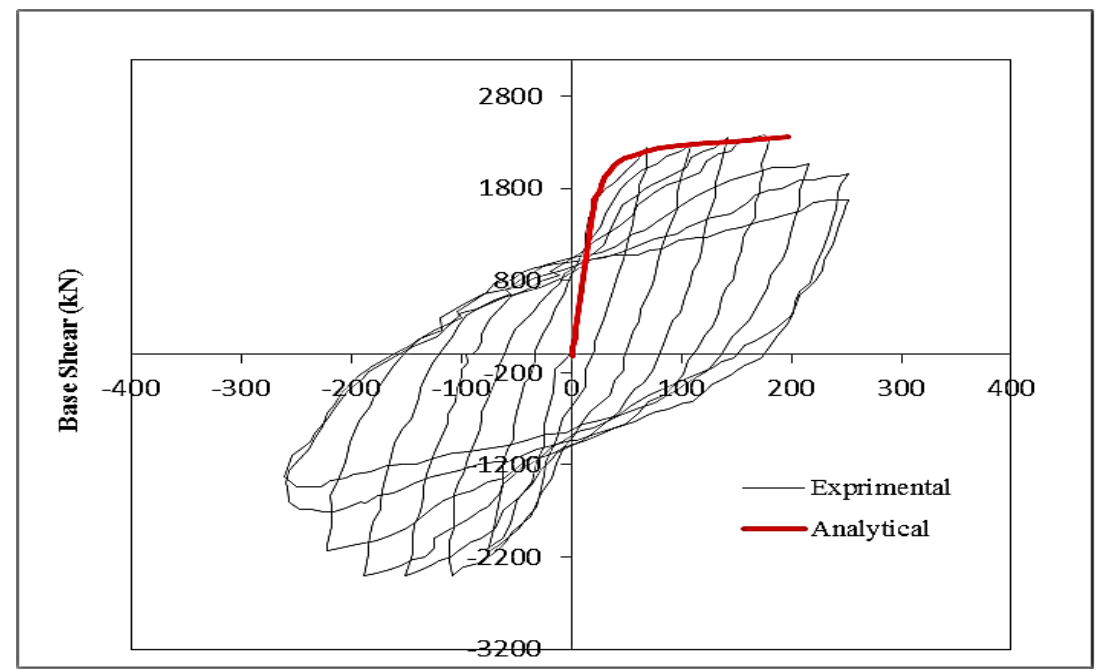

Figure 4: Analytical and experimental force-displacement curves of the wall. 


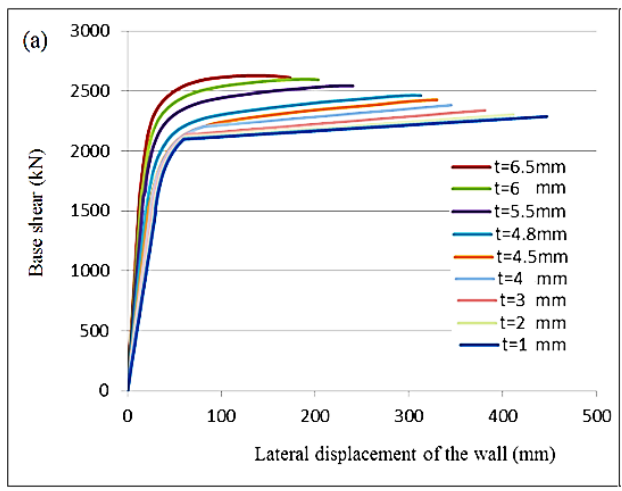

(a) With a concrete cover

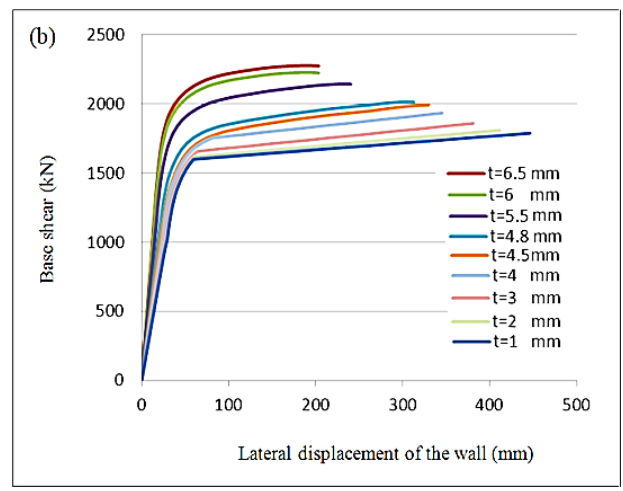

(b) Without a concrete cover

Figure 5: Force-displacement curves for different thicknesses of the steel plate.

\section{Results of Analysis}

\section{Effect of Thickness of the Steel Plate}

As mentioned in the general assumptions section, nine different values were taken for the thickness of the steel plate. Figure 5 shows effects of variation of this parameter on the lateral behaviour of the studied CSW. In this figure, thickness and compressive strength of the concrete cover are $75 \mathrm{~mm}$ and 28 $\mathrm{MPa}$, and spacing of the shear tabs is $300 \mathrm{~mm}$. Effects of variation of the above parameters are assessed in the following sections.

According to the numerical modelling section, instability of the system occurs due to tensile yielding and inelastic buckling of the steel plate and formation of plastic hinges at column bases and ends of beams. The same phenomenon leads to numerical divergence in analysis where the curves of Figure 5 are terminated.

In Figure 5 at the very beginning of the curves (at a lateral force of about $200 \mathrm{kN}$ ), the concrete cover cracks in diagonal tension. It reduces slightly the lateral stiffness. At a much larger lateral force (2000-2500 kN, per case), diagonal tensile and compressive strips of the steel plate yield and in the compressive direction buckle between the shear tabs soon afterwards. From this point, the steel frame alone has to bear with the lateral load. In practice, because of presence of a small gap between the concrete cover and the steel frame, and slenderness of the cover, it does not contribute considerably to transferring the diagonal compression. There is no need to explicitly model the gap. It is enough not to merge the peripheral nodes of the concrete cover with those of the beams and columns. This way, when displacing laterally, the elements can penetrate each other in compression. At the final point of the above curves, a complete plastic hinge has been formed at the base of columns and end of beams, as of Figure 6. As an evidence, the lateral stiffness of the system decreases gradually, as observed, between the yield point of the steel plate (at a lateral force of about $2000-2500 \mathrm{kN}$ ) and the failure point (at a lateral force of $2300-2600 \mathrm{kN}$ ) and reduces to about zero at the latter position.

An interesting fact in Figure 5 is how the failure displacement and ductility of the system decreases for thicker steel plates. The reason for this phenomenon is gradual progression of plastic hinge formation in the boundary elements over thicker steel plate yielding, after which a rapid instable mechanism forms inevitably (Figure 6). For the same reason in Figure 5, as the steel plate thickness increases to 6 times its initial value, the lateral strength increases from 2,300 only to $2,550 \mathrm{kN}$, i.e. only about $11 \%$ increase. At the same time, the lateral stiffness of the CSW increases from 5,111 to $12,439 \mathrm{kN} / \mathrm{mm}$, i.e. about 2.5 times. The lateral stiffness is almost the same for the plate thicknesses over $5 \mathrm{~mm}$. Therefore, it is clear that again yielding of the boundary elements puts a cap on the lateral stiffness value without which, the stiffness would have increased to about 6 times. Also, the ductility capacity of the wall (ratio of the final displacement to the value at yield) decreases from 9 to 4.5. In part (b) of this figure, it is observed that the concrete cover contributes only slightly to the lateral strength of the system.

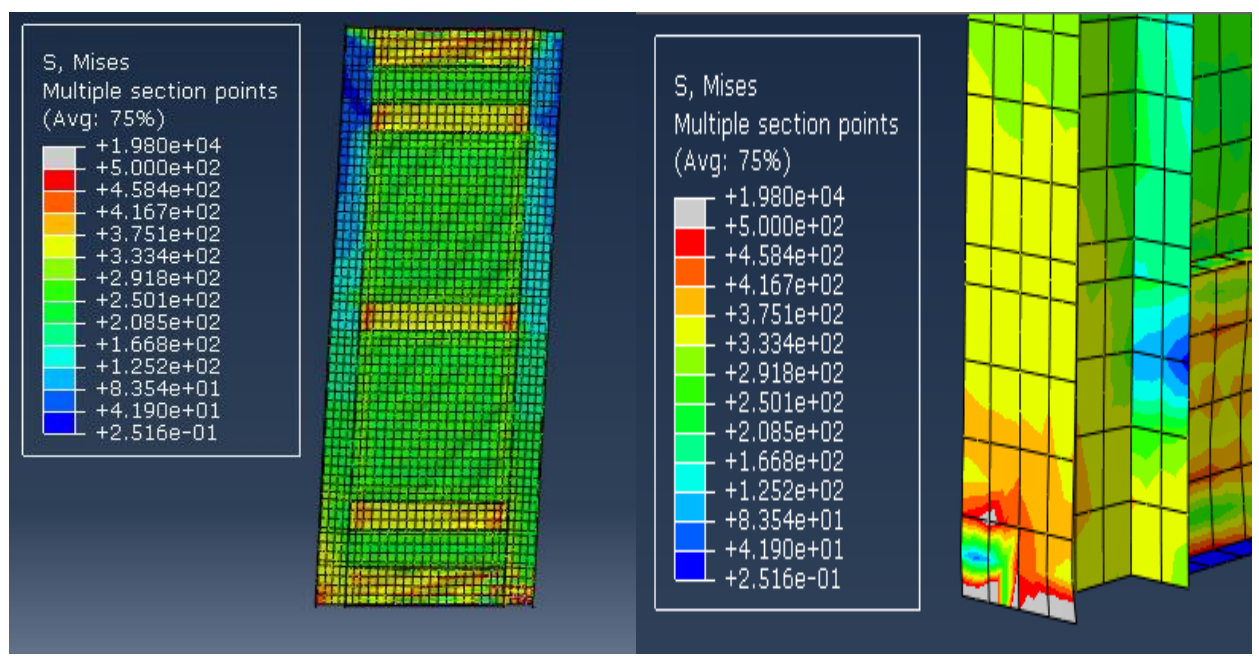

Figure 6: Contours of the von Mises stress; formation of plastic hinges at the base of columns and end of beams. 


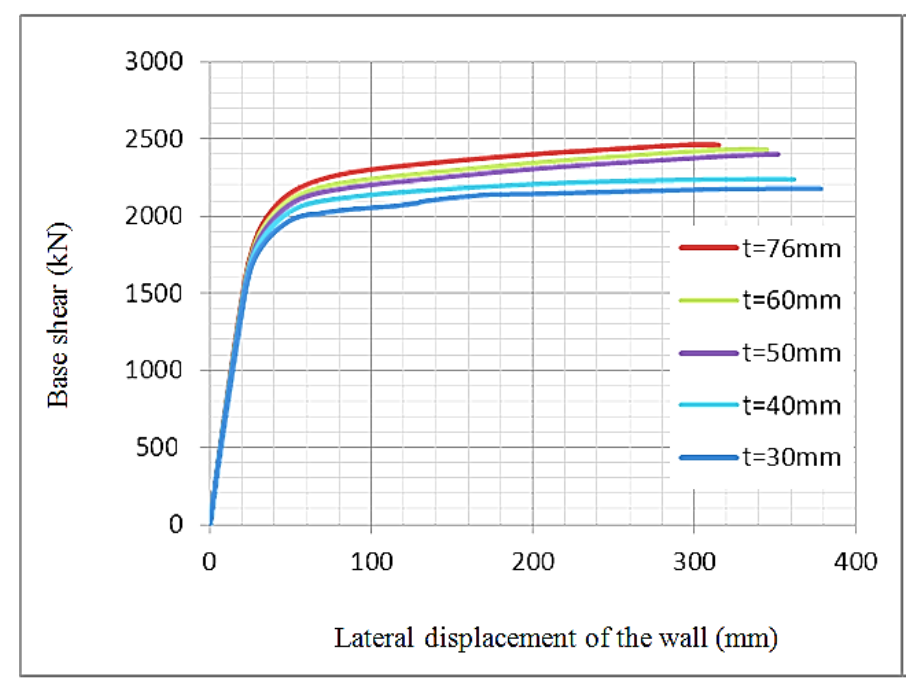

Figure 7: Force-displacement curves of the studied wall for different thicknesses of the concrete cover.

\section{Effect of the Concrete Cover Thickness}

As mentioned in the general assumptions section, five different values have been assumed for thickness of the concrete cover. Figure 7 illustrates effects of variation of this parameter on the force-displacement behaviour of the studied CSW. Values of the plate thickness, compressive strength of concrete cover, and shear tab spacing are $4.8 \mathrm{~mm}, 28 \mathrm{MPa}$, and $300 \mathrm{~mm}$ in this figure.

The curves of Figure 7 clearly agree with the discussion of Figure 5. According to Figure 7, increase of the thickness of concrete cover does not affect the lateral stiffness of the system. This fact shows that after cracking of concrete in tension in the early stages of lateral displacement, stiffness of the system is practically accommodated by the steel plate. Role of the compressive concrete in this regard, especially if a gap exists at the perimeter of the cover, is negligible. After yielding of the steel plate in tension, a thicker concrete cover postpones both yielding of the steel plate in compression and its inelastic buckling and relatively improves the lateral strength of the system. Figure 7 shows that when the cover thickness is increased by 2.5 times, the lateral strength increases only about $12 \%$ and is negligible. Also, increase of cover thickness has had almost no effect on the ductility of the system. This again shows that the system ductility is mainly a function of plastic behaviour of the steel plate agreeing with the discussion in the effect of thickness of the steel plate section.

Distribution of principal strains of the concrete cover is shown in Figure 8 at its final stages of lateral behaviour. It is observed that how the principal compressive strains are developed along the main diagonal of the cover, reaching to their peak at the corners due to stress concentration, and exceeding the presumed capacity of 0.0035 .

\section{Effect of Compressive Strength of the Concrete Cover}

According to the general assumptions section, five values are assigned to the compressive strength of the concrete cover to evaluate its effect on the lateral behaviour of the studied CSW. Figure 9 shows the force-displacement curves of the system under such a variation. In this figure, thicknesses of the steel plate and concrete cover are $4.8 \mathrm{~mm}$ and $76 \mathrm{~mm}$ and spacing of the shear tabs is $300 \mathrm{~mm}$.

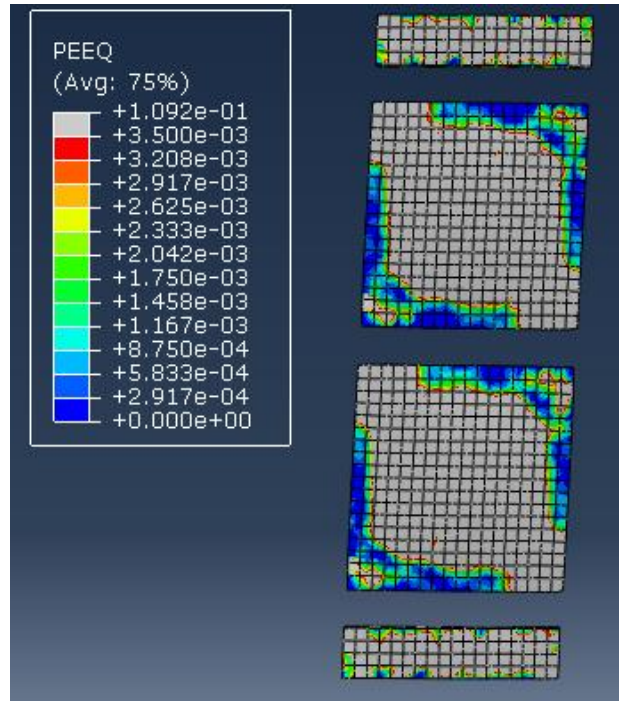

Figure 8: Distribution of principal strains in the concrete cover.

Considering the lateral behaviour of the system as discussed in the sections of effect of thickness of the steel plate and effect of compressive strength of the concrete cover, the trend seen in Figure 9 is according to what is expected. The curves of this figure show that existence of a concrete cover practically has the sole effect of almost concurrent yielding of the steel plate in tension and compression. After that (if the steel plate is not too thick, Figure 5), the tensile strips of the steel plate determine the plastic behaviour of the system. The small effect that increasing the compressive strength of cover has had on improving the system's lateral strength and ductility, has been because of a delayed crushing of the compressive concrete and a little more absorption of the lateral force by the concrete in compression. This is more clearly seen in Figure 10 that illustrates distribution of principal strains of the concrete covers having two different compressive strengths, at equal lateral displacements of the system. This figure shows that at a displacement of $250 \mathrm{~mm}$, the principal compressive strain at the corner of the weaker (i.e., having a smaller compressive strength) concrete cover has exceeded the 0.0035 threshold and peaked at 0.0038 , while its maximum value is 0.0029 in the stronger cover. 


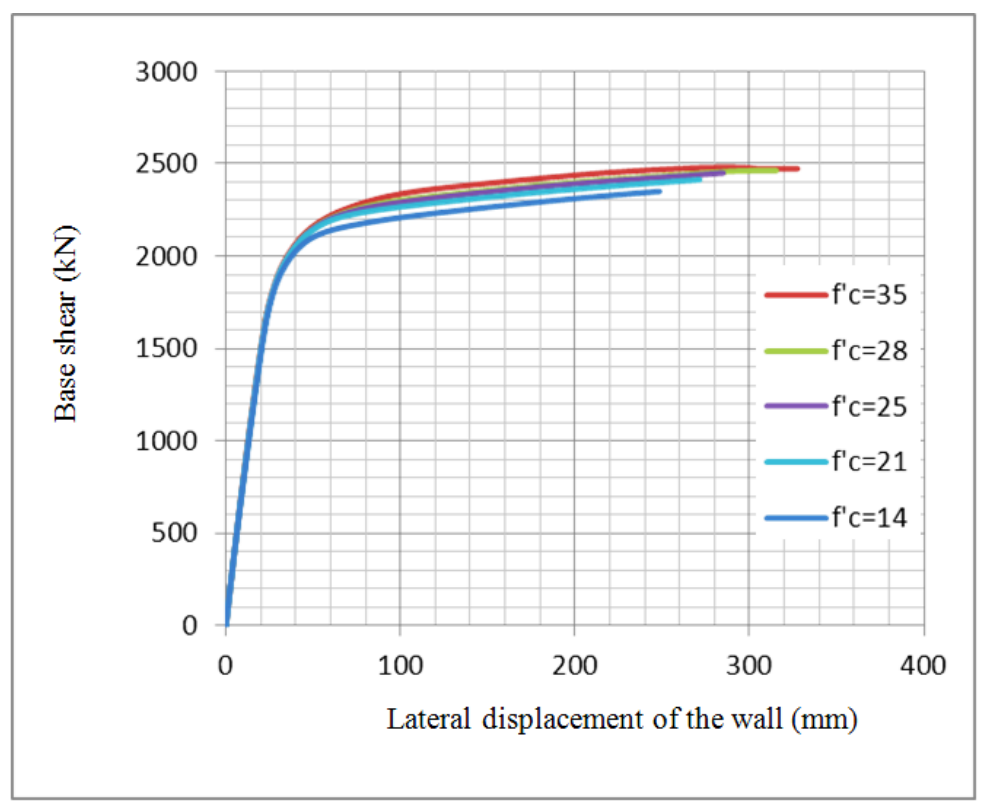

Figure 9: Force-displacement curves of the system for different compressive strengths of the concrete cover (MPa).

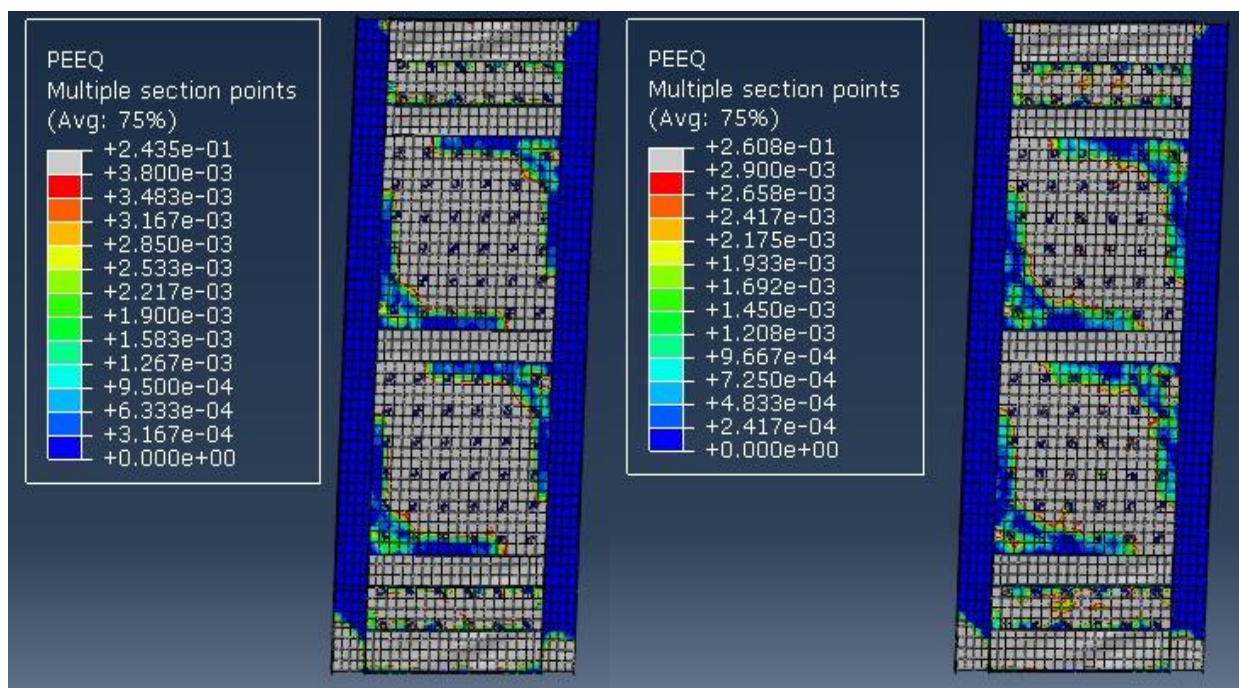

Figure 10: Distribution of principal strains in the concrete cover at a lateral displacement of 250 mm. The compressive strength of the cover is 35 MPa on the left and 14 MPa on the right.

\section{Effect of Spacing of the Shear Tabs}

The shear tab is a small steel component being perpendicular to the core plate surface and extending into the cover concrete to transfer shear loads between the steel core and concrete cover. They can be used as small angles or channels or as heat-welded shear studs. The later is used in this study where circular-section shear studs having a diameter of $13 \mathrm{~mm}$ are at stake. Considering the wall dimensions and conventional values, five different quantities has been taken for the shear tab spacing, according to the general assumptions section. Effect of variation of this parameter on the lateral behaviour of the system is shown in Figure 11. Values of the steel plate and concrete cover thicknesses, and the compressive strength of concrete are $4.8 \mathrm{~mm}, 76 \mathrm{~mm}$, and $28 \mathrm{MPa}$ in this figure. It is anticipated that existence of the shear tabs affect the system's behaviour only after yielding of the steel plate, i.e. when it is necessary for such constraints to restrict detachment of the steel plate from concrete and its lateral buckling as a whole. In this case for smaller spacings, local buckling of the steel plate will happen later and in a slower pace. This fact results in the system's lateral strength to become relatively larger. On the other hand, being able to bear a larger lateral load by the system makes formation of plastic hinges in the frame members to happen earlier after yielding of the steel plate. This fact in turn results in an earlier instability of the system and reduction of its ductility capacity. The curves of Figure 11 well agree with the above discussion. Also, Figure 12 shows that at equal lateral displacements, the maximum stress level is higher in beams and columns for smaller spacings of the shear tabs. According to Figure 11, from a spacing of $450 \mathrm{~mm}$ afterwards, the compression strips of the steel plate buckle in the elastic region and will almost have no effect on the lateral strength capacity of the system. This is shown in Figure 13 for a spacing of 750 $\mathrm{mm}$ at a lateral displacement of $50 \mathrm{~mm}$. 


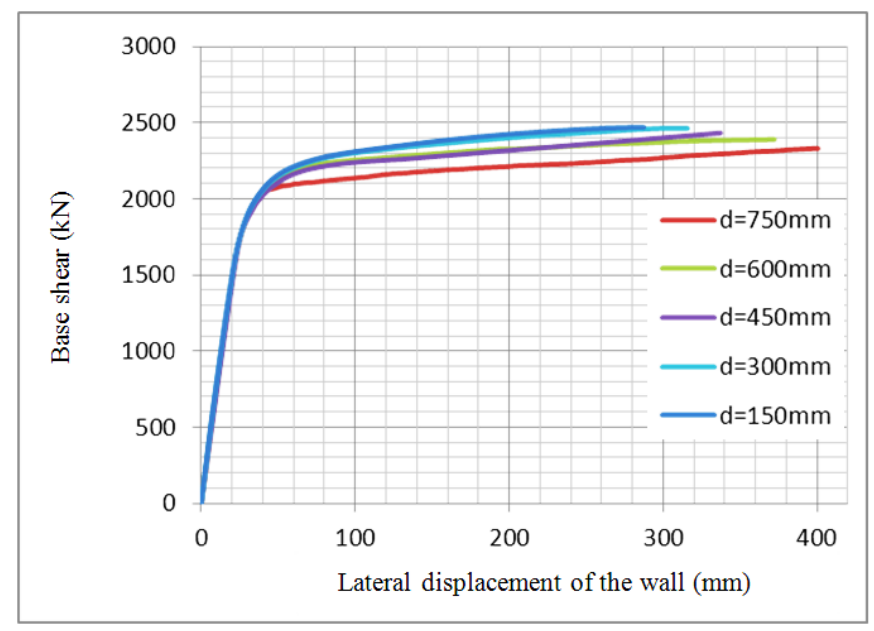

Figure 11: Force-displacement curves of the CSW for different values of shear tab spacing.

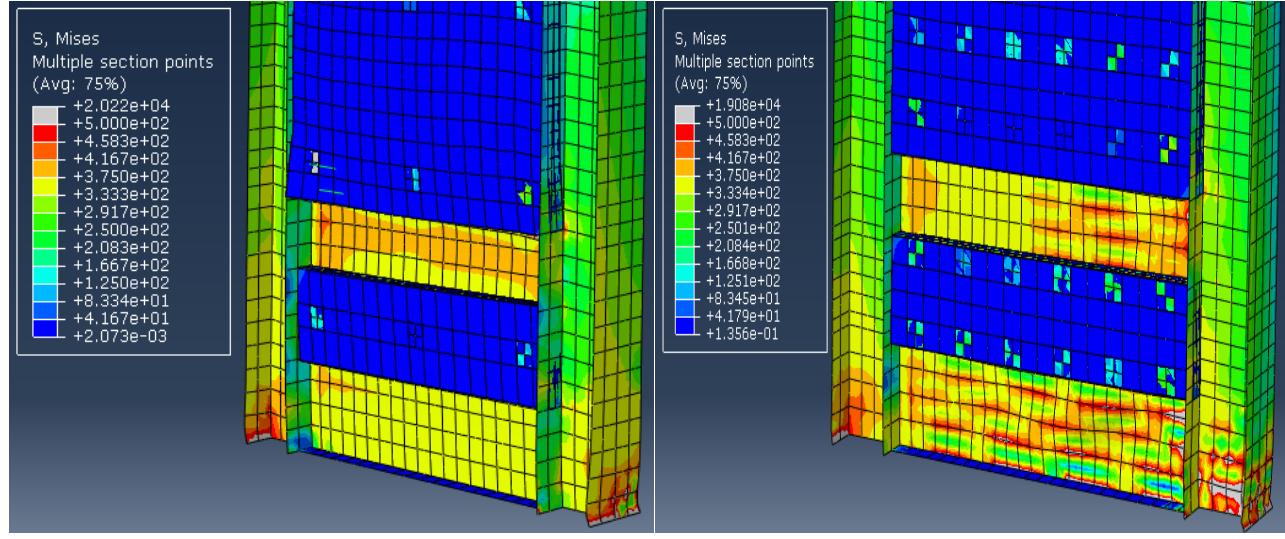

Figure 12: Distribution of the Von Mises stress at a lateral displacement of $250 \mathrm{~mm}$. The shear tab spacing is $750 \mathrm{~mm}$ on the left and $150 \mathrm{~mm}$ on the right.

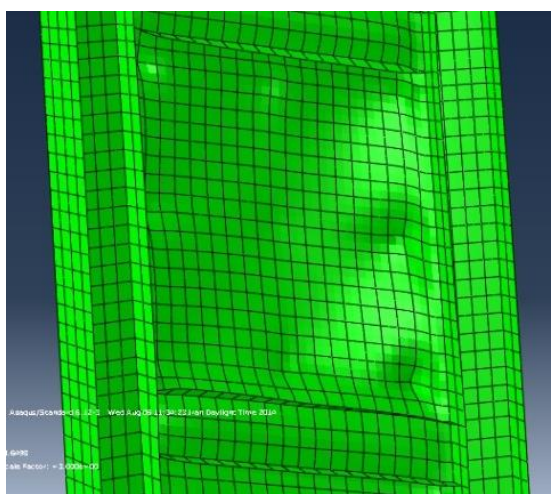

Figure 13: View of the wall at a lateral displacement of 50 mm when the shear tabs are spaced at $750 \mathrm{~mm}$. The steel plate buckles locally in the elastic region.

\section{MACROMODEL FOR CSW IN LATERAL RESPONSE}

\section{The Bilinear Path}

Behaviour of a sample CSW as observed in Figures 5-11, can be simplified by a bilinear path as shown in Figure 14 .

For constructing the bilinear path of Figure 9, ASCE 41-13 [20] is consulted. Then, the areas under the actual and equivalent paths are the same and the first branch of the bilinear path intersects the actual path at $0.6 \mathrm{~V}_{\mathrm{y}}$. The bilinear path of Figure 14 is introduced by the equivalent elastic stiffness $\mathrm{K}_{\mathrm{e}}$, the shear force at yield, $\mathrm{V}_{\mathrm{y}}$, the post-elastic stiffness ratio, $\alpha$, and the shear force capacity, $V_{u}$. Analyses of the parametric study section are utilized for deriving regression equations for the above parameters. Volume of data of the parametric study section is sufficient for this purpose because the parametric study of the mentioned section covers the whole practical range of the parameters involved. On the other hand, for attaining general purpose relations, a couple of other aspect ratios should be accounted for in the analysis. However, as seen in Figure 1, the selected aspect ratio is also a practical one and this fact makes no serious limitation for this study.

Figures of the parametric study section should be used with modification for the purposes of this section. For construction of Figure 14, the net shear force of the steel plate is needed. It is calculated by deduction of shear forces of columns from the story shear in Figure 1 by reading the shear forces at the nodes of the finite element model. Also, the relative displacement of two consecutive beams located at top and bottom of a steel plate segment, instead of the lateral displacement of the system at the top of Figure 1, is necessary. It is extracted from the same analysis of parametric study section. Then, the steel plate's shear force-relative displacement curves of the system of Figure 1 are depicted and results in figures similar in trend to what is presented in parametric study section. These new curves are used for regression analysis of this section. 


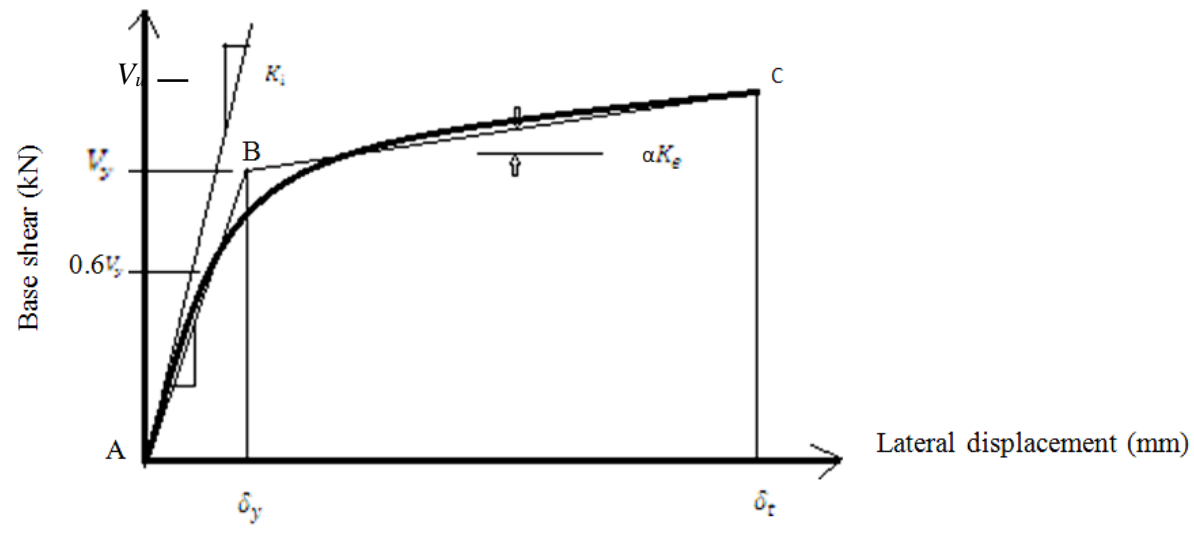

Figure 14. Bilinear substitute for the force-displacement path of CSW in the lateral direction.

\section{Equations for Identifiers of the Bilinear Path}

Equations of the characteristics of the equivalent bilinear path have to be derived with engineering judgment. As discussed in the parametric study section, the elastic lateral stiffness $\left(\mathrm{K}_{\mathrm{e}}\right)$ of a CSW varies only with thickness of the steel plate. But, according to Figure 14, $\mathrm{K}_{\mathrm{e}}$ also depends on the behaviour of the system in the nonlinear range. Based on the parametric study section, the mentioned behaviour is less dependent on concrete strength compared with other parameters. Therefore, $\mathrm{K}_{\mathrm{e}}$ and $\mathrm{\alpha}$ are assumed to be calculated from the following parametric equations:

$\mathrm{K}_{\mathrm{e}}=\alpha_{1} \mathrm{~K}_{\mathrm{sp}}$

$$
\alpha=\alpha_{2} \mathrm{~K}_{\mathrm{psp}} / \mathrm{Ke}
$$

in which $\alpha_{1}$ and $\alpha_{2}$ are regression coefficients, and $K_{s p}$ and $K_{p s p}$ are the elastic and plastic shear stiffnesses of the steel plate, respectively. $\alpha_{1}$ is assumed to change with the thickness of steel plate and concrete, and shear tab spacing. The latter quantities are calculated as:

$\mathrm{K}_{\mathrm{sp}}=\left(\mathrm{G}_{\mathrm{s}} \mathrm{t}_{\mathrm{sp}} \mathrm{b}\right) / \mathrm{h}_{\mathrm{sp}}$

$\mathrm{K}_{\mathrm{psp}}=0.03 \mathrm{~K}_{\mathrm{sp}}$

where $G_{s}$ is the shear modulus of steel, and $t_{s p}, b$, and $h_{s p}$ are thickness, width, and height of the steel plate between its boundary elements. According to the parametric study section, $\mathrm{V}_{\mathrm{y}}$ is strongly dependent only on the thickness of the steel plate. Its dependency on other studied parameters is weak and can be ignored for simplicity.

Then, Equation 9 is derived for $\mathrm{V}_{\mathrm{y}}$ :

$\mathrm{V}_{\mathrm{y}}=\alpha_{3} \tau_{\mathrm{y}} \mathrm{t}_{\mathrm{sp}} \mathrm{b}$

in which $\alpha_{3}$ is the regression coefficient for the yield shear force, and $\tau_{y}$ is the yield stress of steel in shear assumed to be $f_{y} / \sqrt{3}$ with $f_{y}$ being the tensile yield stress of steel. $V_{u}$ can be calculated with a limit plastic analysis and is determined as sum of the ultimate shear capacity of the columns and the steel plate. For the columns, because of formation of bending plastic hinges as discussed in the parametric study section, the ultimate shear capacity is a function of its plastic moment.

Therefore, Equation 10 is developed for calculation of $\mathrm{V}_{\mathrm{u}}$ :

$\mathrm{V}_{\mathrm{u}}=\alpha_{4}\left(\tau_{\mathrm{u}} \mathrm{t}_{\mathrm{sp}} \mathrm{b}+\left(4 \mathrm{M}_{\mathrm{pc}} / \mathrm{h}\right)\right)$

where $\alpha_{4}$ is the regression coefficient for the ultimate shear capacity, $\tau_{u}$ is the ultimate shear stress of steel, being $f_{u} / \sqrt{ } 3$ where $f_{u}$ is the ultimate tensile stress of steel, and $M_{p c}$ and $h$ are the plastic bending capacity and the clear height of the boundary columns, respectively. The latter parameter is assumed to be equal to $h_{\text {sp. }}$.

As described above Equation 7, $\alpha_{1}$ increases with steel and concrete thicknesses and decreases with shear tab spacing.

Then, it is assumed to vary with $t_{c} / d_{s b}$, as a non-dimensional parameter, where $t_{c}$ is thickness of concrete and $d_{s b}$ is distance between the shear tabs. $t_{s p}$ is not considered here because its effect is already present in $\mathrm{K}_{\text {sp. }}$. Figure 15 shows variation of $\alpha_{1}$.

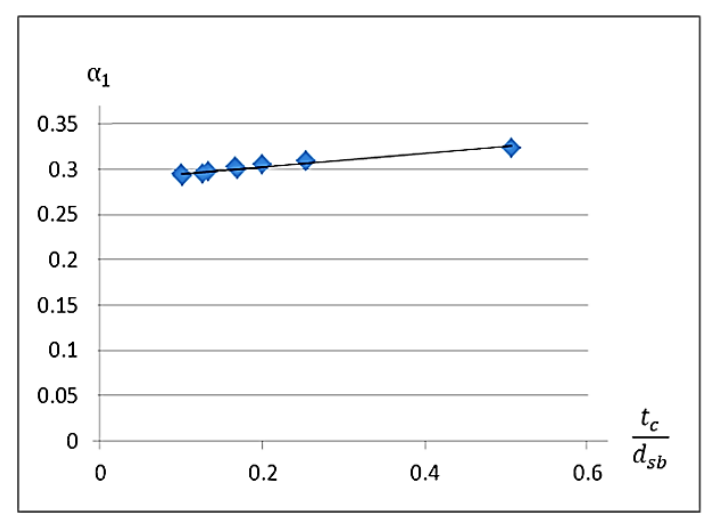

Figure 15: Variation of $\alpha_{1}$.

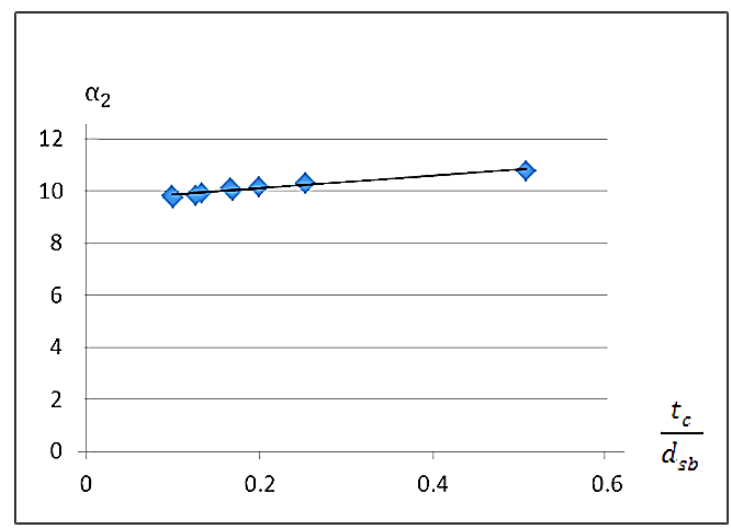

Figure 16: Variation of $\alpha_{2}$.

Then:

$\alpha_{1}=0.0744\left(\mathrm{t}_{\mathrm{c}} / \mathrm{d}_{\mathrm{sb}}\right)+0.2877$

According to results of the parametric study section, $\alpha_{2}$ can also be assumed to be almost independent from $\mathrm{f}^{\prime}{ }_{c}$ and vary with $\mathrm{t}_{\mathrm{sp}}$ and $t_{c}$ directly and with $d_{s b}$ inversely. Because $t_{s p}$ is already 
present in $\mathrm{K}_{\mathrm{psp}}$, then, its variation is calculated to be like Figure 16.

Therefore:

$\alpha_{2}=2.4585\left(\mathrm{t}_{\mathrm{c}} / \mathrm{d}_{\mathrm{sb}}\right)+9.599$

Results of the parametric study section show that $\mathrm{V}_{\mathrm{y}}$ and $\mathrm{V}_{\mathrm{u}}$ increase with $\mathrm{t}_{\mathrm{sp}}, \mathrm{t}_{\mathrm{c}}$, and $\mathrm{f}_{c}^{\prime}$, and decrease with $\mathrm{d}_{\mathrm{sb}}$. Then, they are assumed to vary with the non-dimensional parameter $\left(t_{c}\right.$ $\left./ \mathrm{d}_{\mathrm{sb}}\right)\left(\mathrm{f}^{\prime}{ }_{c} / \mathrm{f}^{\prime}{ }_{c o}\right)$ where $\mathrm{f}^{\prime}{ }_{c o}$ is a reference concrete strength, taken to be $14 \mathrm{MPa}$ in this study. $\mathrm{t}_{\mathrm{sp}}$ is already present in Equations 9 and 10. Figures 17 and 18 show variation of $\alpha_{3}$ and $\alpha_{4}$.

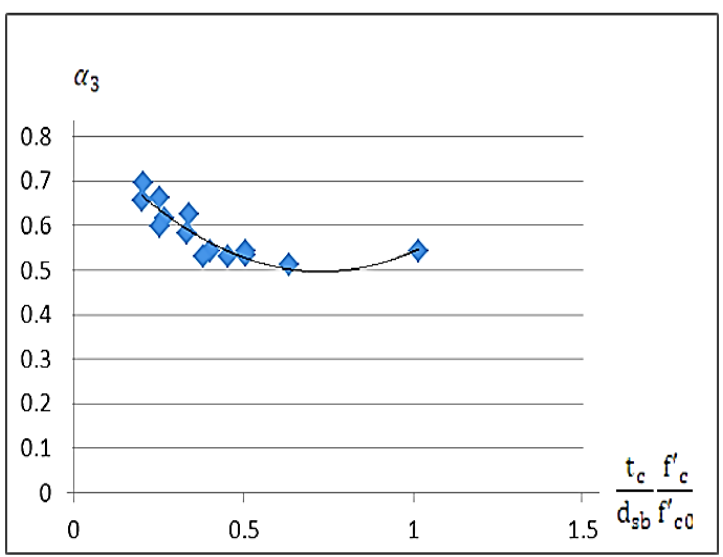

Figure 17: Variation of $\alpha_{3}$.

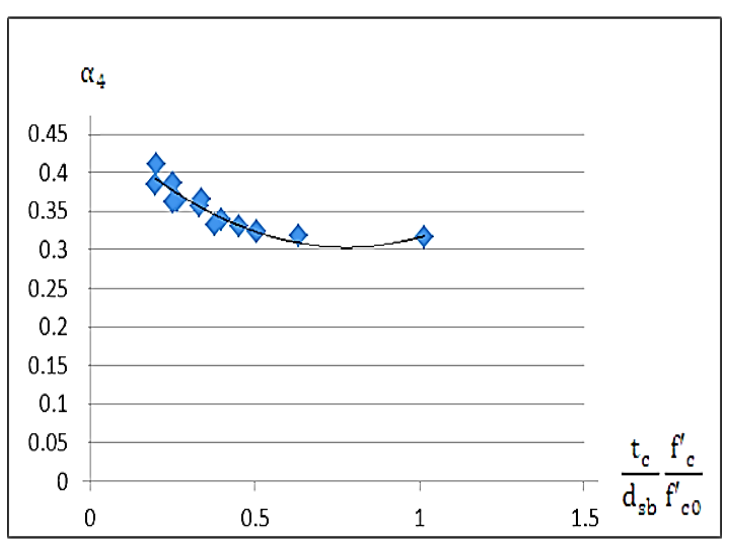

Figure 18: Variation of $\alpha_{4}$.

Then:

$\alpha_{3}=0.6145\left(\left(\mathrm{t}_{\mathrm{c}} / \mathrm{d}_{\mathrm{sb}}\right)\left(\mathrm{f}^{\prime}{ }_{c} / \mathrm{f}^{\prime}{ }_{c o}\right)\right)^{2}-0.8935\left(\left(\mathrm{t}_{\mathrm{c}} / \mathrm{d}_{\mathrm{sb}}\right)\left(\mathrm{f}^{\prime}{ }_{c} / \mathrm{f}^{\prime}{ }_{c o}\right)\right)+0.8212$

$\alpha_{4}=0.2659\left(\left(\mathrm{t}_{\mathrm{c}} / \mathrm{d}_{\mathrm{sb}}\right)\left(\mathrm{f}^{\prime}{ }_{c} / \mathrm{f}^{\prime}{ }_{c o}\right)\right)^{2}-0.4137\left(\left(\mathrm{t}_{\mathrm{c}} / \mathrm{d}_{\mathrm{sb}}\right)\left(\mathrm{f}^{\prime}{ }_{c} / \mathrm{f}^{\prime}{ }_{c o}\right)\right)+0.4642$

\section{The Equivalent Brace}

Figure 14 and its following discussion show that instead of the time consuming 3D modelling and analysis of a CSW, it can easily be replaced with a diagonal homogeneous, say steel, brace with the same equivalent characteristics, as shown for the system of Figure 1 in Figure 19.

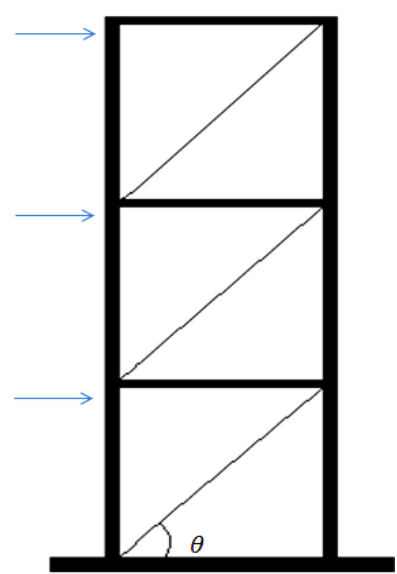

Figure 19: Diagonal braces equivalent to CSWs of Figure 1.

In a computer modelling, section properties of the equivalent brace, including its area, yield stress, $\mathrm{f}_{\mathrm{y}}$, ultimate stress, $\mathrm{f}_{\mathrm{u}}$, and ultimate strain, $\varepsilon_{\mathrm{u}}$, must be introduced.

Using the unit load method, the lateral stiffness of the brace has to be computed such that identical lateral displacements are derived using the brace and the CSW with an equivalent elastic stiffness $\mathrm{K}_{\mathrm{e}}$.

Then it can be shown that:

$\mathrm{A}=\frac{\mathrm{K}_{\mathrm{e}} \mathrm{l}}{\mathrm{E} \cos ^{2} \theta}$

where $A$ is section area, $l$ is length, and $\theta$ is angle of inclination (as of Figure 19), of the equivalent steel brace, and $\mathrm{E}$ is the modulus of elasticity of steel. If the yield and ultimate tensile forces of the equivalent brace are projected onto the horizontal plane, similar capacities of CSW, as of Equations (5) and (6), should be resulted at the same displacements.

Then, the yield and ultimate tensile stresses and the ultimate tensile strain of the equivalent brace are:

$\sigma_{\mathrm{y}}=\mathrm{V}_{\mathrm{y}} /(\mathrm{A} \cos \theta)$

$\sigma_{\mathrm{u}}=\mathrm{V}_{\mathrm{u}} /(\mathrm{A} \cos \theta)$

$\varepsilon_{\mathrm{u}}=\left(\Delta_{\mathrm{u}} \cos \theta\right) / \mathrm{L}$

in which $\Delta_{\mathrm{u}}$ is the lateral drift of CSW at failure.

Validity of the equivalent brace is shown by solving an example different from the cases of the parametric study section. A one story CSW is analysed with the exact 3D finite element method and the simple macromodel equivalent brace. The boundary elements and the story dimensions are similar to Figure 1 and the mechanical properties of steel and concrete materials are as described in the numerical modelling section. Figure 20(a) shows comparison of the exact and approximate forcedisplacement curves in this case. A very good accuracy in lateral response prediction of the actual system is observed in a much simpler and more rapid approach, at least for CSWs having almost rectangular panels as the wall samples of this study. In addition, the curves of Figure 11 are reproduced with the proposed macromodel and compared in Figure 20(b) with those of the finite element model as an example. Again the same good accuracy is observed. 
(a)

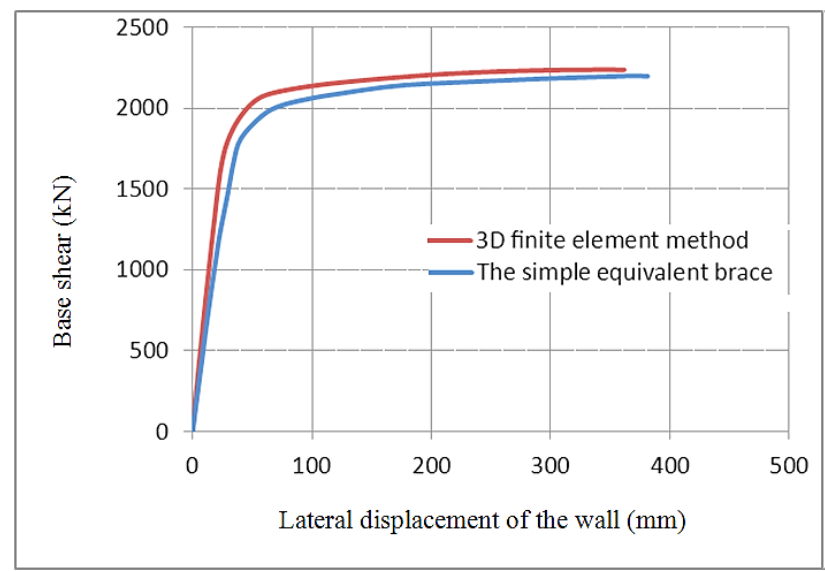

(b)

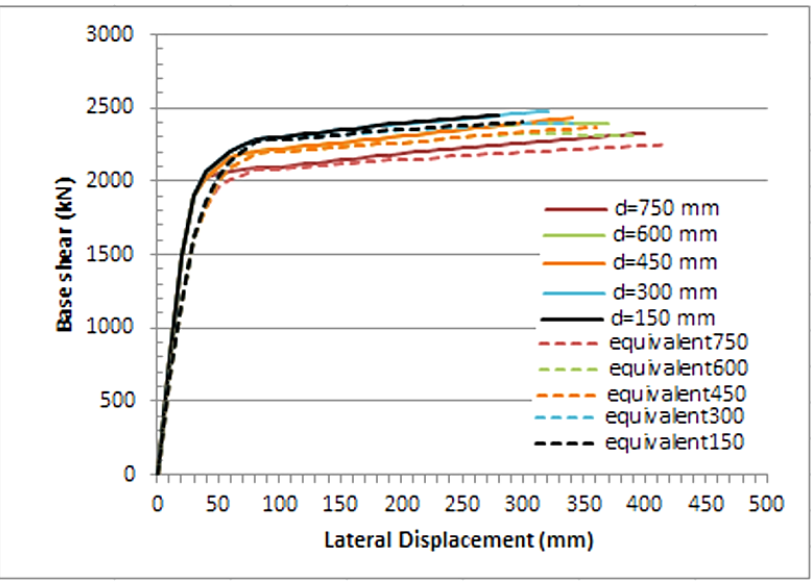

Figure 20: Force-displacement curve of CSW with equivalent brace in comparison to the $3 D$ finite element method. (a) $t_{s p}=4.8 \mathrm{~mm}, t_{c}=40 \mathrm{~mm}, f_{c}^{\prime}=28 \mathrm{MPa}$. (b) The same cases as of Figure 11.

\section{CONCLUSIONS}

In this study, effects of different parameters including thickness of the steel plate, thickness and compressive strength of concrete, and shear tab spacing on the lateral behaviour of composite shear walls (CSW's) were investigated. Thickness of the steel plate was recognized to be the prime factor affecting the behaviour both in the elastic and in the plastic regions. Thickness of the concrete cover and shear tab spacing came afterwards in importance but only in the plastic region and compressive strength of the concrete cover had the least effect. Regression equations for the equivalent elastic stiffness, the yield and ultimate shear forces and the post-elastic stiffness of CSW were developed based on the above analysis for CSW's having almost rectangular panels. It made possible derivation of a macromodel consisting simply of a diagonal steel brace with characteristics in nonlinear lateral behaviour much similar to an actual CSW. Accuracy of the proposed macromodel was confirmed in a representative example.

This study investigated the response of a wall of one aspect ratio, but with two different thicknesses. It would be expected that broadly similar trends hold for walls with a similar aspect ratio. However, walls that have very different aspect ratios (much taller/more slender or much shorter/mores squat) may not necessarily follow the exact same behaviour. Further research is needed if the model is to be generalized to walls that are of a very different aspect ratio to that investigated in this study.

\section{REFERENCES}

1 Astaneh-Asl A (2002). "Seismic Behaviour and Design of Composite Steel Plate Shear Walls". Steel TIPS Report, Structural Steel Educational Council, CA, 49pp.

2 Yamakaji $\mathrm{T}$ and Yamada M (2000). "Resisting Characteristics of Hybird Center Core Shear Wall Systems". $12^{\text {th }}$ World Conference on Earthquake Engineering, Auckland, NZ.

3 Zhao Q and Astaneh-Asl A (2004). "Cyclic Behaviour of Traditional and Innovative Composite Shear Walls". Journal of Structural Engineering, ASCE, 130(2): 271-284.

4 Zhao Q and Astaneh-Asl A (2007). "Seismic Behaviour of Composite Shear Wall Systems and Application of Smart Structures Technology". International Journal of Steel Structures, 7(7): 69-75.

5 Choi IR and Park HG (2008). "Hysteresis Model of Thin Infill Plate for Cyclic Nonlinear Analysis of Steel Plate Shear Walls". Journal of Structural Engineering, ASCE, 136(11): 1423-1434.

6 Qu B, Bruneau M, Lin CH and Tsai KC (2008). "Testing of Full Scale Two-Storey Steel Plate Shear Wall with Reduced Beam Section Connections and Composite Floors". Journal of Structural Engineering, ASCE, 134(3): 364-373.

7 Hatami F and Rahai A (2009). "Behaviour of Composite Shear Walls under Seismic Loading”. Journal of Sharif University of Technology, 46: 21-31.

8 Arabzadeh N, Soltani M and Ayazi A. (2011). "Experimental Investigation of Composite Shear Walls 
under Shear Loadings". Thin-Walled Structures, 49: 842854

9 Husem M, Pul S, Yozgat E and Gorkem SE (2011). "Fracture of Connections between Steel and Reinforced Concrete Shear Walls under the Cyclic Loading". International Journal of Science and Technology, 36(1): 97-102.

10 Ayazi A, Ahmadi H and Shafai S (2012). "The Effects of Bolt Spacing on Composite Shear Wall Behaviour". International Journal of Civil and Environmental Engineering, 6(10): 882-889.

11 Guo L, Li R, Qin R and Zhang S (2012). "Cyclic Behaviour of SPSW and CSPSW in Composite Frame". Thin-Walled Structures, 51: 39-52.

12 Dastfan M and Driver R (2016). "Large-Scale Test of a Modular Steel Plate Shear Wall with Partially Encased Composite Columns". Journal of Structural Engineering, ASCE, 142(2): 04015142.

13 Dastfan M and Driver R (2018). "Test of a Steel Plate Shear Wall with Partially Encased Composite Columns and RBS Frame Connections". Journal of Structural Engineering, ASCE, 144(2): 04017187.

14 Rahnavard R, Hassanipour A and Mounesi A (2016). "Numerical Study on Important Parameters of Composite
Steel-Concrete Shear Walls". Journal of Constructional Steel Research, 121: 441-456.

15 Rassouli B, Shafaei S, Ayazi A and Farahbod F (2016). "Experimental and Numerical Study on Steel-Concrete Composite Shear Wall Using Light-Weight Concrete". Journal of Constructional Steel Research, 126: 117-128.

16 Sabouri-Ghomi S, Jahani Y and Bhowmick AK (2016). "Partial Interaction Theory to Analyze Composite (SteelConcrete) Shear Wall Systems under Pure Out-of-Plane Loadings". Thin-Walled Structures, 104: 211-224.

17 Shafaei S, Ayazi A and Farahbod F (2016). "The Effect of Concrete Panel Thickness upon Composite Steel Plate Shear Walls". Journal of Constructional Steel Research, 117: 81-90.

18 Bruhl JC and Varma AH (2017). "Experimental Resistance and Available Ductility of Steel-Plate Composite Walls in One-Way Bending”. Journal of Structural Engineering, ASCE, 143(4): 04016222.

19 3DS (2013). "Abaqus Analysis User's Manual, Version 12.3". Dassault Systems.

20 ASCE (2013). “ASCE 41: Seismic Evaluation and Upgrade of Existing Buildings". American Society of Civil Engineers, Reston, Virginia. 